\title{
Lung function in school-aged asthmatic children with inhaled cromoglycate, nedocromil and corticosteroid therapy
}

\author{
K. Korhonen, M. Korppi, S.T. Remes, T.M. Reijonen, K. Remes
}

\begin{abstract}
Lung function in school-aged asthmatic children with inhaled cromoglycate, nedocromil and corticosteroid therapy. K.Korhonen, M. Korppi, S.T. Remes, T.M. Reijonen, K. Remes. (C) ERS Journals Ltd 1999.

ABSTRACT: Two-thirds of the children with asthma in our area use cromones and only one-third steroids as the maintenance therapy. This study aimed to evaluate our treatment policy based on the international consensus.

Peak expiratory flow (PEF), dynamic spirometry and bronchodilation test results were therefore collected in 195 school-aged patients who visited our outpatient clinic in 1995 . Sixty-four children (33\%) used cromoglycate, $86(44 \%)$ nedocromil and 45 $(23 \%)$ inhaled steroids. Twenty-five $(\mathbf{1 2 \%})$ needed combination therapy, mainly with salmeterol.

Lung function results were good, and there were no significant differences between the therapeutic groups irrespective of whether pre- or postbronchodilator values were considered. PEF was decreased in eight (4\%), forced expiratory volume in one second (FEV1) in four (2\%) and maximum mid-expiratory flow (MMEF) in 33 (17\%) patients. At least one result was decreased in $39(20 \%)$ cases, in most cases $(77 \%)$ MMEF alone. Significant rises after salbutamol inhalations were observed in $17(9 \%)$ in PEF, in two (1\%) in FEV1 and $20(10 \%)$ in MMEF values. Thus, the bronchodilation test was positive in $33(17 \%)$ cases, and in $22(11 \%)$ cases it was the only sign of bronchial obstruction.

Over $70 \%$ of the children with asthma can be treated with cromones by a stepwise treatment modality. Inhaled steroids can be restricted to those not controllable by cromones. Lung function tests, including postbronchodilator values, should be part of the follow-up of continuous maintenance medication for asthma.

Eur Respir J 1999; 13: 82-86.
\end{abstract}

Dept of Paediatrics, Kuopio University Hospital, Kuopio Finland

Correspondence: K. Korhonen

Dept of Paediatrics

Kuopio University Hospital

FIN-70210 Kuopio

Finland

Fax: 35817172410

Keywords: Asthma

bronchodilatation test

children

cromone therapy

lung function

steroid therapy

Received: December 71997

Accepted after revision August 131998
The international consensus statement on the diagnosis and therapy of asthma in children was published in 1989 and revised in 1991. According to this consensus, antiasthma drugs should be used on the basis of the severity of asthma: cromoglycate (or nedocromil) in mild to moderate cases and inhaled steroids in severe cases $[1,2]$. We have previously published our experiences about the consensus-based treatment policy; for years, $\sim 70 \%$ of the asthmatic children who need maintenance therapy have been treated by cromones and $<30 \%$ by inhaled steroids in our area [3]. This policy is different from that of most other centres [4]. Based on our previous retrospective clinical and lung function data, the children treated with nonsteroidal anti-inflammatory drugs had their asthma under good control [5].

Lung function results were collected in 195 schoolaged children with asthma treated by continuous antiinflammatory medication according to the principles of the international consensus. Both pre- and postbronchodilator values were available. The aim of the study was to evaluate whether the selected anti-inflammatory therapy (cromoglycate, nedocromil or inhaled steroid) was sufficient for asthma control in the children.

\section{Patients and methods}

The Department of Paediatrics, Kuopio University Hospital, provides consultation services for children from a defined area, the province of Kuopio. The child population in this area is $\sim 50,000$. The only outpatient clinic for asthmatic children is in this hospital, and the treatment policy is planned and supervised by the paediatric allergist. The guidelines are in accordance with the international consensus; children with mild to moderate asthma are treated with cromoglycate or nedocromil, and children with severe asthma, and those not responding to cromone therapy, with inhaled steroids [1-3].

During the surveillance period of 12 months, from January 1, 1995 to December 31, 1995, 216 children with asthma ( 128 males and 88 females) aged $\geq 6$ yrs visited the outpatient clinic for asthmatic children, and were examined by the paediatric allergist (K. Remes) of our study group according to a prospective schedule. Children with acute infection, insufficient treatment compliance, and poor co-operation in lung function tests were not enrolled; they were re-examined 3-4 months later and then enrolled if possible. In addition, 21 children who had not used the 
same anti-inflammatory drug for a minimum of 3 months, were excluded. The remaining 195 children formed the study group: 64 (33\%) used cromoglycate (group A), 86 (44\%) nedocromil (group B), and 45 (23\%) either beclomethasone $(n=3)$ or budesonide $(n=42)$ (group $C)$.

The usual dose of budesonide was $0.4 \mathrm{mg}^{- \text {day }^{-1}}$; the dose of $0.8-1.6 \mathrm{mg} \cdot \mathrm{day}^{-1}$ was used if needed. However, the children requiring $0.8 \mathrm{mg} \cdot$ day $^{-1}$ continuously were transferred to the combination therapy. In the present study, 25 $(12 \%)$ patients needed combination therapy, salmeterol in 24 cases and theophylline in one case; one belonged to group A, 11 to group B and 13 to group C. The dosage of nedocromil varied from $8-16 \mathrm{mg} \cdot \mathrm{day}^{-1}$ and that of cromoglycate from $20-40 \mathrm{mg} \cdot$ day $^{-1}$.

Sympathomimetic drugs were allowed to be used on demand during asthmatic symptoms, i.e. wheezing or cough. During acute infections, doubling the maintenance dose for 1-3 weeks was advised. For the same time, additional inhaled steroids are allowed for selected patients on continuous cromoglycate or nedocromil therapy. If the patients had used both cromones and steroids during the preceding 3 months, they were excluded from the analysis. Our practice is to regard symptom control as acceptable when asthmatic symptoms are present and sympathomimetics are used on $<3$ days a month. Long-acting sympathomimetics and/or slow-release theophylline are added to the regimen only in those cases not controllable by maximal doses of anti-inflammatory drugs.

During control visits at the outpatient clinic, peak expiratory flow (PEF) (Wright's PEF meter $\AA$; Ferris Medi-

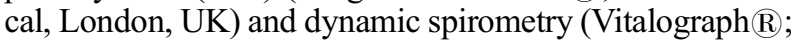
G.W. Berg \& Co., Buckingham, UK) were routinely performed in all children over the age of 5-6 yrs. The severity of asthma was classified in each child into five categories according to the symptoms during the preceding 3 months [6]. The PEF measurement was performed three times; the best value of the three accurate flows was recorded. The reliability of the result in dynamic spirometry was controlled by the shape of the curve; the test was repeated if the shape was irregular. The variables determined in spirometry were forced vital capacity (FVC), forced expiratory volume in one second (FEV1), FEV1/FVC ratio (FEV\%), and maximal mid-expiratory flow (MMEF) between 25 and $75 \%$ of FVC [7-9]. The results were compared with the height-related reference values from Finnish children [10], and are expressed as percentages from the means of the references (percentage predicted). The $75 \%$ level was regarded as the lower normal limit for FEV1 and PEF, and the $65 \%$ level for MMEF; in the FEV\% measurement, a result of $<75 \%$ was considered as decreased $[7,8]$. The respective limits for severely decreased levels were defined as $50 \%$ for $\mathrm{FEV} 1, \mathrm{FEV} \%$ and $\mathrm{PEF}$, and $40 \%$ for MMEF [8].

After baseline measurements, a bronchodilatation test with inhaled salbutamol or terbutaline was performed in all children. Postbronchodilator PEF and dynamic spirometry measurements were performed after $15 \mathrm{~min}$. In the bronchodilatation test, the limit of positivity was a $\geq 15 \%$ increase in PEF or FEV1 values, and a $33 \%$ or greater increase in MMEF values [8, 11, 12].

In statistical analysis, the SPSS statistical package was used (SPSS, Chicago, IL, USA). The Chi-squared test was used in paired comparisons; if the size of at least one cell was $<5$, Fisher's exact probability test was used. One-way analysis of variance (ANOVA) was used for the comparison of group means and the paired t-test for further analyses. The Bonferroni correction was used in all paired analyses [13]. Ninety-five per cent confidence intervals (CI) were used to describe the distributions of the values within the groups, and to evaluate the magnitude of the overlap between the groups.

\section{Results}

The proportion of males was $64 \%$ in both cromone groups and $44 \%$ in the steroid group (NS). The mean age was 9.3 yrs (SD 2.5) in group A, 11.5 yrs (SD 2.1) in group $\mathrm{B}$ and 11.2 (SD 2.6) in group $\mathrm{C}$. The children in the cromoglycate group were younger than those in the other groups $(\mathrm{p}<0.01$ versus group $\mathrm{B}$ and $\mathrm{p}<0.05$ versus group C).

Approximately $25 \%$ of the children had suffered from symptoms suggestive of respiratory infection during the 4 weeks before the investigation. The children who had symptomatic infection at the control visit were not enrolled. There were no significant differences between the groups either in the frequency of respiratory infections or in the duration of symptoms (data not shown).

The mean $(95 \% \mathrm{CI})$ total duration of anti-inflammatory therapy for asthma was 4.3 yrs (3.6-5.1) in the cromoglycate, 5.5 yrs (4.8-6.3) in the nedocromil and 5.4 yrs (4.56.4 ) in the steroid group (NS). Thirty-nine children had used anti-inflammatory medication longer than 5 yrs; during the study, 13 (33\%) of them used steroids, 21 (54\%) nedocromil and only five (13\%) cromoglycate (table 1$)$.

In the present study, the assessment of the severity of asthma reflects asthmatic symptoms during maintenance therapy. Only three children (2\%) had severe asthma symptoms. None belonged to the groups "no symptoms of asthma" or "very severe asthma". The children taking cromones more often had mild symptoms while children taking steroids more often had moderate symptoms (table 2).

On average, prebronchodilator lung function results were good in all treatment groups. The mean values of PEF, FVC, FEV 1 and FEV\% were $>95 \%$ of that predicted in all groups (fig. 1). In addition, the lower limits of the $95 \%$ CIs were at the level of $>90 \%$ of predicted values. Correspondingly, the mean MMEFs were over $85 \%$, and the lower limits of the CIs $>80 \%$. There were no statistically significant differences in any of the measured variables

Table 1. - Duration of anti-inflammatory therapy in the 195 children with asthma requiring continuous maintenance with cromoglycate, nedocromil or inhaled steroids

\begin{tabular}{|c|c|c|c|c|}
\hline $\begin{array}{l}\text { Duration of anti- } \\
\text { inflammatory } \\
\text { therapy }\end{array}$ & $\underset{(n=63)}{\text { Group A }}$ & $\begin{array}{c}\text { Group B } \\
(\mathrm{n}=84)\end{array}$ & $\begin{array}{c}\text { Group C } \\
(\mathrm{n}=44)\end{array}$ & p-value \\
\hline$<24$ months $(\mathrm{n}=85)$ & $31(49)$ & $33(39)$ & $21(48)$ & 0.43 \\
\hline $2-4 \mathrm{yrs}$ & 27 (43) & $30(36)$ & $10(23)$ & 0.10 \\
\hline$\geq 5$ yrs & $5 \quad(8)$ & $21(25)^{*}$ & $13(29)^{* *}$ & $=0.010$ \\
\hline
\end{tabular}

Values are presented as $\mathrm{n}(\%)$. Group A: cromoglycate therapy; group B: nedocromil therapy; group C: budesonide therapy. *: $\mathrm{p}<0.05$ versus group $\mathrm{A} ;{ }^{* *}: \mathrm{p}<0.01$ versus group $\mathrm{A}$ for differences between the groups. When groups A and B were combined as the cromone group, the differences between it and the steroid group were not statistically significant. 
Table 2. - Severity of asthma symptoms during the past three months in children taking cromoglycate, nedocromil or steroid therapy

\begin{tabular}{|c|c|c|c|c|}
\hline Symptom score & $\begin{array}{c}\text { Group A } \\
(\mathrm{n}=64)\end{array}$ & $\begin{array}{c}\text { Group B } \\
(\mathrm{n}=86)\end{array}$ & $\underset{(n=45)}{\text { Group C }}$ & p-value \\
\hline $\begin{array}{l}\text { Mild symptoms }{ }^{\#} \\
(\mathrm{n}=130)\end{array}$ & $47(73)^{*}$ & $61(71)^{*}$ & $22(49)$ & 0.015 \\
\hline $\begin{array}{l}\text { Moderate symptoms } \\
(\mathrm{n}=62)\end{array}$ & $17(27)$ & $23(27)$ & $22(49)^{+}$ & 0.019 \\
\hline $\begin{array}{l}\text { Severe symptoms } \\
\quad(\mathrm{n}=3)\end{array}$ & 0 & $2(2)$ & $1(2)$ & 0.55 \\
\hline
\end{tabular}

Values are presented as $\mathrm{n}(\%)$. Group A: cromoglycate therapy; group B: nedocromil therapy; group C: budesonide therapy. \# barely noticeable; ${ }^{\S}$ : noticed from time-to-time but not severe enough to cause significant discomfort and interfere with daily routine; ${ }^{*}$ : noticed often and caused significant discomfort to interfere with daily routine. ${ }^{*}: \mathrm{p}<0.05$ versus group $\mathrm{C} ;{ }^{+}: \mathrm{p}<0.05$ versus groups $\mathrm{A}$ and $\mathrm{B}$. When groups $\mathrm{A}$ and $\mathrm{B}$ were combined, the difference was significant between it and the steroid group in the number of cases with both mild $(\mathrm{p}<0.01)$ and moderate $(\mathrm{p}<0.01)$ symptoms.

between the three therapeutic groups. Likewise, the groups did not differ, when postbronchodilator spirometry results were analysed (fig. 2). Some difference was seen in postbronchodilator PEF values: they were higher in group A than in group B. However, there were no significant differences in any variable, when the changes between pre- and postbronchodilator results were analysed (data not shown).

Decreased results in PEF $(<75 \%)$ were observed in eight $(4 \%)$, in FEV1 $(<75 \%)$ in four $(2 \%)$ and in MMEF $(<65 \%)$ in $33(17 \%)$ patients (table 3$)$. Severely decreased values were not seen. There were no significant differences between the groups. At least one pathological result was present in nine (14\%) patients in group A, in $20(23 \%)$ in group B and in $10(22 \%)$ in group $\mathrm{C}(\mathrm{NS})$. The result was the same, if groups A and B were combined (cromone group).

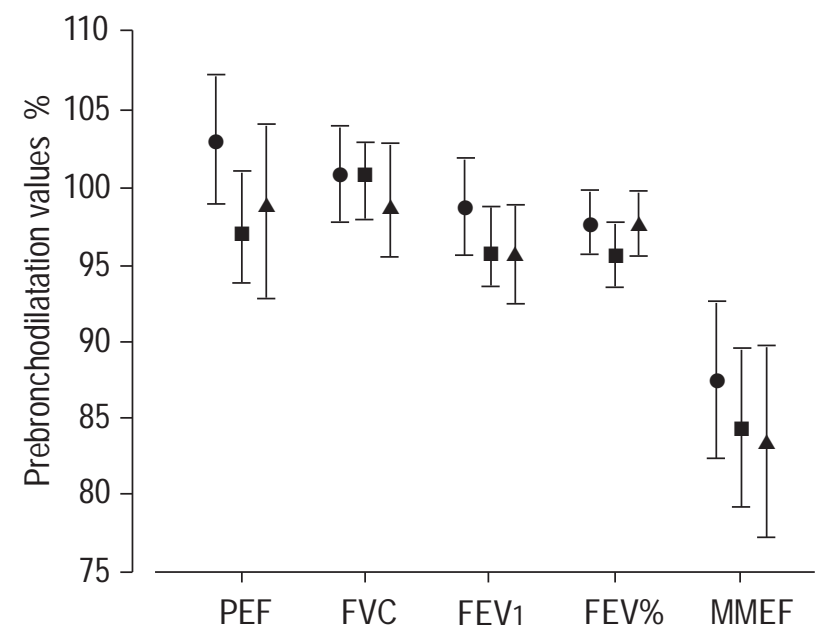

Fig. 1. - Baseline (prebronchodilator) lung function results (means, $95 \%$ confidence intervals) in 195 children with asthma requiring continuous maintenance. ๑: group A, cromoglycate therapy; ש: group B, nedocromil therapy; $\mathbf{\Delta}$ : group $\mathrm{C}$, budesonide therapy. PEF: peak expiratory flow; FVC: forced vital capacity; FEV1: forced expiratory volume in one second; $\mathrm{FEV} \%$ : FEV1/forced vital capacity ratio; $\mathrm{MMEF}$ : maximum mid-expiratory flow.

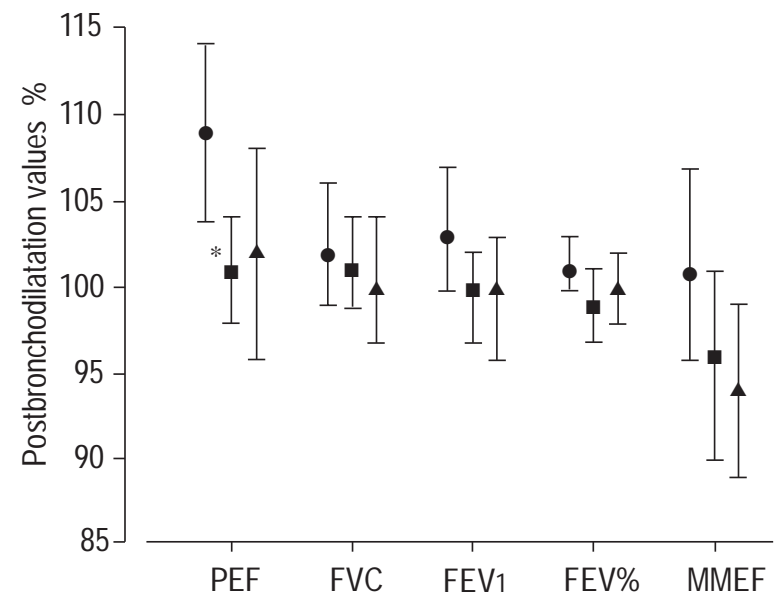

Fig. 2. - Postbronchodilator lung function results (means, 95\% confidence intervals) in 195 children. - group A, cromoglycate therapy; group $\mathrm{B}$, nedocromil therapy; $\boldsymbol{\Delta}$ : group $\mathrm{C}$, budesonide therapy. *: $\mathrm{p}<0.05$, group A versus group B. For definitions see legend to figure 1 .

Significant rises $(>15 \%)$ after salbutamol inhalation were observed in $17(9 \%)$ children in PEF, in two (1\%) in FEV1 and in $20(10 \%)$ in MMEF values (table 4). At least one significant rise was present in $15(23 \%)$ children in group A, in $12(14 \%)$ in group B and in six $(13 \%)$ in group C (NS). If groups $\mathrm{A}$ and $\mathrm{B}$ were combined, a significant rise was present in $27(18 \%)$ of the patients using cromones, as compared with $13 \%$ in those using steroids (NS).

When the decreased PEF, FEV1 and MMEF results were combined, at least one pathological value was present in $39(20 \%)$ patients; $11(28 \%)$ of them had and $28(72 \%)$ did not have diagnostic rises in the bronchodilation test (table 5). The bronchodilation test was pathological in 33 $(17 \%)$ cases; 11 patients $(33 \%)$ had and $22(67 \%)$ did not have decreased prebronchodilator values. When the prebronchodilator (decreased values) and postbronchodilator (significant rises) results are combined, at least one subnormal result was seen in $50(26 \%)$ patients. The figure

Table 3. - Lung function results in the 195 children in the three treatment groups

\begin{tabular}{lrrrrr}
\hline $\begin{array}{l}\text { Significant } \\
\text { decrease }\end{array}$ & All & \multicolumn{6}{c}{ Group A } & Group B & Group C \\
& groups & $(\mathrm{n}=64)$ & $(\mathrm{n}=86)$ & $(\mathrm{n}=45)$ & -value \\
\hline PEF & $8(4)$ & 0 & $5(6)$ & $3(7)$ & 0.29 \\
FEV1 & $4(2)$ & $2(3)$ & $1(1)$ & $1(2)$ & 0.65 \\
PEF or FEV1 & $10(5)$ & $2(3)$ & $5(6)$ & $3(7)$ & 0.43 \\
MMEF & $33(17)$ & $7(11)$ & $18(21)$ & $8(18)$ & 0.27 \\
PEF or FEV1 & $39(20)$ & $9(14)$ & $20(23)$ & $10(22)$ & 0.35 \\
or MMEF & & & & &
\end{tabular}

Values are presented as $\mathrm{n}(\%)$. Group A: cromoglycate therapy; group B: nedocromil therapy; group C: budesonide therapy. The lower normal limit for peak expiratory flow (PEF) and forced expiratory volume in one second (FEV1) was $75 \%$ and for maximum mid-expiratory flow (MMEF) 65\%, calculated from the means of the height-related reference values (percentage predicted). FEV\% denotes the FEV1/forced vital capacity (FVC) ratio; the lower normal limit was $75 \%$, and the result was normal in every child. There were no significant differences between the groups. When groups A and B were combined to the cromone group, the differences between it and the steroid group were also not statistically significant. 
Table 4. - Bronchodilation test results in the 195 children in the three therapeutic groups

\begin{tabular}{lrrrrr}
\hline $\begin{array}{l}\text { Significant } \\
\text { rise }\end{array}$ & All & \multicolumn{4}{c}{ Group A Group B Group C } \\
groups & $(\mathrm{n}=64)$ & $(\mathrm{n}=86)$ & $(\mathrm{n}=45)$ & p-value \\
\hline PEF & $17(9)$ & $9(14)$ & $6(7)$ & $2(4)$ & 0.20 \\
FEV1 & $2(1)$ & $1(2)$ & $1(1)$ & 0 & 0.59 \\
PEF or FEV1 & $19(10)$ & $10(16)$ & $7(8)$ & $2(4)$ & 0.14 \\
MMEF & $20(10)$ & $9(14)$ & $7(8)$ & $4(9)$ & 0.49 \\
PEF or FEV1 & $33(17)$ & $15(23)$ & $12(14)$ & $6(13)$ & 0.24 \\
or MMEF & & & & & \\
\hline
\end{tabular}

Values are presented as $\mathrm{n}(\%)$. Group A: cromoglycate therapy; group B: nedocromil therapy; group C: budesonide therapy. The limit for the significant rise was $15 \%$ for peak expiratory flow (PEF) and forced expiratory volume in one second (FEV1), and $33 \%$ for maximum mid-expiratory flow (MMEF). There were no significant differences between the groups. When groups A and $\mathrm{B}$ were combined, the differences between it and the steroid group were also not statistically significant.

was $28(14 \%)$ if only pathological PEF or FEV1 results were considered.

\section{Discussion}

In the present study, the proportion of children on longterm cromoglycate or nedocromil medication was $77 \%$ of those requiring continuous maintenance therapy for asthma. Only $23 \%$ of the patients were on therapy with inhaled steroids; this figure is lower than in many other child populations, and clearly lower than in adult asthmatics $[5$, $14,15]$. According to our treatment policy, selected patients on continuous cromone maintenance are allowed to use inhaled steroids for 1-3 week periods during acute respiratory infections. Systemic steroids are allowed only for acute symptoms treated in hospital. During the present surveillance, $<5 \%$ of the patients had used systemic steroids or inhaled steroids in addition to cromones in the past 3 months, and they were excluded from the analysis.

On average, asthma was held under good control in children in all three treatment groups. The mean values of all the measured variables were over $85 \%$ of those predicted in all groups. Moreover, the lower limits of $95 \%$ CIs were above the lower normal limit of each variable, $>65 \%$ for MMEF and $>75 \%$ for the others $[5,8,9]$. There were no significant differences between the treatment groups; this result was the same in pre- and postbronchodilator measurements, as well as when the changes between them were analysed. However, there was a trend that bronchodilator therapy caused more improvement in the cromoglycate group than in other groups. This may speak for insufficient treatment balance in some patients.

In the PEF measurements, decreased values were seen in $5 \%$ and significant rises after salbutamol inhalation in $9 \%$ of patients; the respective proportions were $1-2 \%$ in FEV1 measurements. The most sensitive variable, MMEF, was decreased in $17 \%$, and it rose significantly in the bronchodilatation test in $10 \%$ of the subjects. In previous studies, $17-26 \%$ of asthmatic children have had decreased MMEF, 29\% diagnostic rises in MMEF, 2\% decreased $\mathrm{PEF}, 8 \%$ decreased $\mathrm{FEV} 1$, and $48 \%$ a $>20 \%$ diurnal variation in PEF $[9,12,16,17]$. In a recent study from northern Finland, $23 \%$ of children had a significant rise in FEV1 and $29 \%$ in MMEF values [12]. Thus, our results speak for a good treatment control, better than in most previous studies, in children of all treatment groups. On the other hand, we did not use any challenge tests to assess underlying bronchial hyperreactivity, and to show mild imbalance not demonstrable by baseline or postbronchodilator lung function.

In all, $50(26 \%)$ children had at least one subnormal lung function result: 28 only in baseline PEF or spirometry, 22 only in the bronchodilatation test, and 11 in both. The subnormal results were evenly distributed between the treatment groups. These patients may represent asthma cases with insufficient maintenance medication, but the figures are, however, lower than reported by other authors $[9,12,16,17]$. Moreover, severely decreased values were not present at all, and in the clinical evaluation only three children had severe asthma symptoms. The bronchodilatation test revealed asymptomatic bronchial obstruction in $11 \%$ of the patients, thus speaking for inadequate therapy in those children [12]. The 28 cases with lung function abnormalities not responding to salbutamol inhalations may represent cases with chronic airway inflammation. Their proportion, $14 \%$, is rather high, but this figure was mostly, in $68 \%$, based on MMEF values alone. PEF or FEV1 changes not reversed by salbutamol, which have a more clear clinical impact, were seen in $<5 \%$.

Table 5. - Comparison between lung function and bronchodilation test results

\begin{tabular}{lccccc}
\hline & \multicolumn{3}{c}{ Baseline lung function decreased $^{+}$} & \\
\cline { 2 - 4 } & $\begin{array}{c}\text { Any method } \\
(\mathrm{n}=39)\end{array}$ & $\begin{array}{c}\mathrm{PEF} \\
(\mathrm{n}=8)\end{array}$ & $\begin{array}{c}\mathrm{FEV} 1 \\
(\mathrm{n}=4)\end{array}$ & $\begin{array}{c}\text { MMEF } \\
(\mathrm{n}=33)\end{array}$ & $\begin{array}{c}\text { Normal lung function } \\
(\mathrm{n}=156)\end{array}$ \\
\hline $\begin{array}{l}\text { Either PEF or FEV1 or MMEF } \\
(\mathrm{n}=33)\end{array}$ & $11(28)$ & 1 & 1 & 11 & $22(14)$ \\
$\begin{array}{l}\text { PEF } \\
(\mathrm{n}=17)\end{array}$ & 8 & 1 & 1 & 8 & 9 \\
$\begin{array}{l}\text { FEV1 } \\
(\mathrm{n}=2)\end{array}$ & 0 & 0 & 0 & 0 & 2 \\
$\begin{array}{l}\text { MMEF } \\
(\mathrm{n}=20)\end{array}$ & 3 & 0 & 0 & 3 & 17 \\
$\begin{array}{l}\text { Normal result } \\
(\mathrm{n}=162)\end{array}$ & $28(72)$ & 7 & 3 & 22 & $134(86)$ \\
\hline
\end{tabular}

Values are presented as $\mathrm{n}(\%)$. The limit for the significant rise was $15 \%$ for peak expiratory flow (PEF) and forced expiratory volume in one second (FEV1), and 33\% for maximum mid-expiratory flow (MMEF). The lower normal limit for the PEF and FEV 1 was $75 \%$ and for MMEF $65 \%$, calculated from the means of the height-related reference values (percentage predicted). 
Preventive therapy should be started early in the course of asthma [1, 2, 18]. Whether the treatment should begin with steroidal or nonsteroidal drugs is open to debate. The cromones are less effective than steroids, but they have virtually no side-effects $[1,2]$. The results of the present study confirm our previous observations that $\sim 70 \%$ of asthmatic children who need maintenance therapy can be treated with cromoglycate or nedocromil, at least in our area [5]. The children in the cromoglycate group were younger than those in the two other groups. This may signify a progression from this group to the others by increasing age. Despite this age difference, the results confirm the usefulness of the international guidelines on the stepwise management of childhood asthma based on the severity of the disease and its symptoms $[1,2]$. These conclusions are in accordance with the result of a recent follow-up study where $50 \%$ of children treated by cromones or steroids, but only $17 \%$ of those with no maintenance, showed significant clinical and lung function improvement [19].

These results show that the planning of maintenance therapy, and the selection of patients between the available alternatives, was, for the most part, appropriate. In agreement with our previous observations and those of other study groups, the follow-up of asthmatic children in an allergy clinic leads to an increased use of anti-inflammatory drugs, and decreased hospital admissions and emergency room visits $[5,20]$. This increase concerns cromones more than steroids; the continuous use of inhalative steroids can be restricted to those cases not responding to nonsteroidal alternatives. In Sweden, though the prevalence of childhood asthma has increased, hospital admissions and emergency room visits for it have decreased. This has been explained by the earlier introduction and increased use of anti-inflammatory drugs, mainly inhalative steroids, in childhood asthma [21]. There is a lack of respective population-based data about the influence of the use of cromones, and the implementation of international guidelines.

In conclusion, asthma in children can be held in good control by choosing the therapy according to the severity of the disease $[1,2,6,19]$. By this policy, the majority (over $70 \%$ of the children who need maintenance therapy) can be treated with cromones $[3,5]$. The use of inhaled steroids can be restricted to the patients with severe asth$\mathrm{ma}$, or to the cases not controlled by cromones. Lung function tests, including postbronchodilator values, should be included in the follow-up of children with continuous maintenance therapy for asthma.

\section{References}

1. Warner J, Göntz M, Landau L, et al. Management of asthma: a consensus statement. Arch Dis Child 1989; 64: $1065-1079$.

2. Warner J, Neijens H, Landau L, et al. Asthma: a followup statement from an international paediatric asthma consensus group. Arch Dis Child 1992; 67: 240-248.

3. Korppi M, Kuikka L, Remes K. Preventive therapy for asthma in children; a 9-year experience in Eastern Finland. Eur Respir J 1995; 8: 1318-1320.

4. Warner JO. Review of prescribed treatment for children with asthma. $B r$ Med $J$ 1995; 311: 663-666.

5. Korppi M, Remes K. Asthma treatment in schoolchildren: lung function in different therapeutic groups. Acta Paediatr 1996; 85: 190-194.

6. Stewart GE II, Diaq JD, Lockey RF, Seleznick MJ, Trudeau WL, Ledford DK. Comparison of oral pulse methotrexate with placebo in the treatment of severe glucocorticosteroid-dependent asthma. J Allergy Clin Immunol 1994; 94 : 482-489.

7. Solymar L, Aronsson P-H, Bake B, Bjure J. Nitrogen single breath test; flow-volume curves and spirometry in healthy children, 7-18 years of age. Eur Respir Dis 1980; 61: 275-286.

8. Lebeque P, Kiakulanda P, Coates A. Spirometry in the asthmatic child: is FEF $25-75$ a more sensitive test than FEV1/FVC? Pediatr Pulmonol 1993; 16: 19-22.

9. Korppi M, Kuikka L, Reijonen T, Remes K, JuntunenBackman K. Bronchial asthma and hyperreactivity after early childhood bronchiolitis or pneumonia: an 8-year follow-up study. Arch Pediatr Adolesc Med 1994; 148: 1079-1084.

10. Salorinne Y. Reference values for flow-volume spirometry in children. Proceedings: VIIIth Scandinavian Congress of Clinical Physiology. Helsinki, Finland 1989; Abstract 30. Clin Physiol 1990; 10 (3): 257-303.

11. Sovijärvi A, Uusitalo A, Länsimies E, Vuori I, eds. In: Kliininen Fysiologia (Clinical Physiology). Kustannus Oy Duodecim. Gummerus Kirjapaino OY. Jyväskylä, Finland, 1994; pp. 99-103.

12. Linna O. Spirometry, bronchodilator test or symptom scoring for the assessment of childhood asthma. Acta Pediatr 1996; 85: 564-569.

13. Zar JH. Biostatistical Analysis, 2nd ed. Englewood Cliffs, NJ, Prentice-Hall, 1984; pp. 402-403.

14. Carlsen K-H. Epidemiology of childhood asthma. Eur Respir Rev 1994; 4: 5-9.

15. Vermeire P. Growing consensus in asthma? Eur Respir $J$ 1992; 5: 509-511.

16. Sly P, Landau L, Weymoth R. Home recording of peak expiratory flow rates and perception of asthma. Am J Dis Child 1985; 139: 479-482.

17. Bye M, Kerstein D, Barsh E. The importance of spirometry in the assessment of childhood asthma. Am J Dis Child 1992; 146: 977-981.

18. Östergaard P, Nielsen J. Medical treatment of asthmatic children before referral to a clinic for allergy. A comparison between the periods 1979-83 and 1988-91. Allergy 1994; 49: 390-392.

19. König P, Shaffer J. The effect of drug therapy on longterm outcome of child hood asthma: a possible pretriew of the international guidelines. J Allergy Clin Immunol 1996; 98: 1103-1111.

20. Mahr T, Evans R. Allergist influence on asthma care. Ann Allergy 1993; 71: 115-120.

21. Wennergren G, Kristjánsson S, Strannegård I-L. Decrease in hospitalisation for childhood asthma with increase use of anti-inflammatory treatment, despite an increase in the prevalence of asthma. J Allergy Clin Immunol 1996; 97 : $742-748$. 